\title{
Gestão escolar democrática no MST: \\ a Escola Eduardo Galeano
}

Democratic school management inside MST:

Eduardo Galeano School

Gestión escolar democrática en el MST:

el Colegio Eduardo Galeano

THALES MOURA BRASIL ALEGRO*

Universidade Federal de Alfenas, Alfenas- MG, Brasil.

EVERTON RODRIGUES DA SILVA*

Universidade Federal de Alfenas, Alfenas- MG, Brasil.

\begin{abstract}
RESUMO: A gestão democrática é um dos eixos fundamentais do arranjo organizativo do Movimento dos Trabalhadores Rurais Sem Terra (MST), tem a participação como componente garantidor da democracia e a educação no movimento segue o mesmo norte. Entretanto, suas escolas, frequentemente, estão ligadas a secretarias estaduais ou municipais de educação para obter reconhecimento pelo Ministério da Educação e Cultura. É o caso da Escola Eduardo Galeano, investigada nesta pesquisa, que entrou em funcionamento no segundo semestre de 2016 e funciona como extensão - ou segundo endereço - de uma escola na área urbana. O objetivo desta pesquisa foi compreender as singularidades da gestão democrática escolar praticada pelo MST, tendo como referência a tensão entre dois modelos de gestão.

Palavras-chave: MST. Gestão participativa. Gestão democrática. Educação do campo.
\end{abstract}

\footnotetext{
* É graduado em História e mestre em Gestão Pública e Sociedade pela Universidade Federal de Alfenas. Atua como educador em História no ensino público estadual de Minas Gerais. E-mail: <thalesalegro@gmail.com>.

** É mestre em Ciências em Administração pela Universidade Federal do Rio de Janeiro e doutor em Administração pela Universidade Federal de Minas Gerais. Atua como professor na Universidade Federal de Alfenas. E-mail: <everton.silva@unifal-mg.edu.br>.
} 
ABSTRACT: Democratic management is one of the fundamental basis in the organizational arrangement from the Brazilian Landless Farmworkers' Movement (MST). It has participation as guaranteed component of democracy and education inside the movement heading to the same direction. However, its schools are often linked to state or city education departments in order to obtain recognition from the Education and Culture Ministries. It is the case of Eduardo Galeano School, investigated in this research, which began operating in the second semester of 2016 and functions as an extension, or second address, for a school located in the urban area. The objective of this research is to understand the singularities of the democratic school management practiced by the MST, having the tension between two models of management as reference.

Keywords: MST. Participative management. Democratic management. Rural education.

RESUMEN: La gestión democrática es uno de los ejes fundamentales del ordenamiento organizativo del Movimiento de Trabajadores Rurales Sin Tierra (MST), con la participación como componente que garantiza la democracia y la educación en el movimiento que sigue el mismo norte. Sin embargo, sus escuelas a menudo están vinculadas a departamentos de educación estatales o municipales para obtener el reconocimiento del Ministerio de Educación y Cultura. Este es el caso del Colegio Eduardo Galeano, estudiado en esta investigación, que comenzó a operar en el segundo semestre de 2016 y funciona como una extensión --o segunda dirección-- de un colegio en el área urbana. El objetivo de esta investigación fue comprender las singularidades de la gestión escolar democrática practicada por el MST, teniendo como referencia la tensión entre dos modelos de gestión.

Palabras clave: MST. Administración participativa. Gestión democrática. Educación rural.

\section{Introdução}

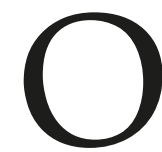
significado do conceito de gestão democrática tem se tornado um campo de disputa entre setores da sociedade brasileira que reinterpretam esse modelo de gestão conforme os seus interesses. Do mesmo modo, no ambiente escolar, 
o conceito encontra fronteiras na medida em que esbarra em compreensões individualizadas dos gestores que assumem as direções de escolas, sendo legitimadas pelo grupo de funcionários e comunidade escolar em geral. A Constituição Federal de 1988 incorporou a gestão democrática como demanda dos movimentos sociais. Entretanto, o que se deu, a partir disso, foi a elaboração de diferentes interpretações para o texto com a intenção de legitimar projetos políticos contrastantes. O artigo 206, do Capítulo VI da Constituição, garante que o ensino será ministrado com base no princípio da "gestão democrática do ensino público, na forma da lei" (BRASIL, 1988), mas não determina os contornos para essa gestão. Para Dalila Andrade Oliveira, "a leitura que se faz dos termos gestão e democracia e, ainda mais, da combinação entre ambos varia conforme os projetos em disputa" (OLIVEIRA, 2015: 95). O que tem ocorrido na prática é que, embora haja o estímulo por mecanismos de maior participação na gestão, sua apropriação pelos modelos administrativos advindos dos poderes político e econômico hegemônicos acaba por ressignificar os processos de deliberação, dando-lhes uma expressão consensual, quando, na verdade, continuam perpetuando relações autoritárias e desiguais.

Na contramão de uma escola libertadora, os modelos educacionais têm caminhado de mãos dadas com os interesses do modelo político-econômico ao qual está inserida a maior parte dos países e também o Brasil. A autora Lucia Bruno, no artigo Poder e administração no capitalismo contemporâneo, defendeu que a gestão educacional tem se aproximado cada vez mais da gestão empresarial. Como explicou:

trata-se de garantir o que nas empresas denomina-se qualidade total. Entretanto,
esta qualidade refere-se primordialmente à qualidade do processo, não do produto,
já que, com relação a este, a qualidade é sempre referida ao segmento do mercado
ao qual se destina. Qualidade do processo produtivo diz respeito à redução de des-
perdícios, de tempo de trabalho, de custos, de força de trabalho (BRUNO, 2016: 41).

A autora ainda menciona que o sistema econômico contribui para que instituições transnacionais, como o Banco Mundial, que recomendam o investimento em equipamentos em detrimento da qualificação de professores, sejam os agentes de uma educação voltada para as necessidades do mercado, inclusive segmentando os investimentos em regiões e, por consequência, também o tipo de trabalho que é incentivado em cada território. Bruno argumentou que a guinada neoliberal dos novos governos pelo mundo tende a aumentar essas diferenças regionais de investimentos e também a desigualdade social.

Por outro lado, a construção de uma escola voltada ao desenvolvimento da autonomia de seus alunos não está restrita a qualquer ferramenta de governos por uma deliberação verticalizada. O pedagogo Paulo Freire, no capítulo Ninguém liberta ninguém, ninguém se liberta sozinho: os homens se libertam em comunhão, que compõe a obra Pedagogia do Oprimido, alertou para o fato de que promover relações dentro da escola que sejam efetivamente pedagógicas na busca pela emancipação das partes envolvidas ultrapassa um 
ato de mera concessão, no qual o indivíduo é colocado em uma posição de decisão sem que tenha consciência do processo de libertação em que está inserido.

No Brasil, o modelo de gestão escolar praticado pelo MST tem como contribuição radical colocar a todos como corresponsáveis por uma escola que favoreça sua emancipação e luta por direitos sociais, uma vez que se reconheçam na posição de oprimidos. Como explicou Freire, "a presença dos oprimidos na busca por sua libertação, mais do que pseudoparticipação, é o que deve ser: engajamento" (FREIRE, 2016: 101).

O modelo de educação desenvolvido pelo MST diverge daquele aplicado no ensino habitual das escolas públicas em diversos aspectos. Para Dal Ri e Vieitez (2004), o ensino e o trabalho voltados para as características particulares do movimento estão associados à necessidade de valorização da identidade daqueles que fazem parte desse meio. Considera-se, assim, a formação para o trabalho, sendo este o ambiente conhecido e praticado pelos alunos durante seu percurso. Ou seja, o aluno se forma para trabalhar no campo e na comunidade da qual já faz parte e, por isso, se identifica com o processo de aprendizagem, uma vez que ele condiz com a sua realidade.

Há diferenças estruturais entre as escolas ligadas ao MST e a maioria das escolas públicas de ensino regular. Todavia, neste artigo, a singularidade que gostaríamos de acentuar diz respeito aos modelos de gestão democrática adotados por ambas. Pela nossa experiência como pesquisadores, observamos que, seguindo um procedimento consonante com outros níveis de organização do MST, as escolas localizadas dentro dos assentamentos ou acampamentos utilizam um modelo democrático na gestão e na tomada de decisões. Alunos, professores e funcionários decidem juntos sobre aspectos pedagógicos, políticos, administrativos e orçamentários. Esse modelo de gestão escolar é diferente do modelo verificado em outras escolas, o qual, embora apresente uma estrutura democrática legal, não demonstra capacidade de efetivação desses mecanismos normativos em sua gestão.

Motivado por essa dicotomia, foi realizado um estudo de caso na Escola Eduardo Galeano, cujo objetivo geral foi compreender as singularidades da gestão democrática escolar praticada pelo MST, tendo como referência a tensão entre ambos os modelos de gestão educacional. A escola entrou em funcionamento no segundo semestre de 2016 e estava localizada em um acampamento ${ }^{1}$ na zona rural da cidade de Campo do Meio, Sul de Minas Gerais. O fato de estar localizada em um espaço ilegal criou uma especificidade fundamental, que justifica essa investigação: dada a situação de ilegalidade, a escola não pôde existir de forma independente. A solução foi torná-la uma extensão - ou segundo endereço - da Escola Estadual Dr. José Mesquita Netto, localizada na área urbana de Campo do Meio. Dessa forma, a gestão da Escola Eduardo Galeano teve que ser permanentemente negociada com a direção "oficial”, em outra instituição e em outro espaço e que não tinha identidade com os princípios do MST. 
Essa situação tornou evidente a tensão entre modelos de gestão com ideologias, normas e práticas tão distintas. Além disso, o processo ocorreu no pano de fundo de intensa luta e reivindicação por parte do MST junto ao Governo de Minas Gerais pelo direito à ocupação do espaço habitado por cerca de 600 famílias, onde a Escola Eduardo Galeano se localiza. A tensão chegou a níveis não administráveis pelo movimento e culminou com o fechamento da escola no final de 2018. O cenário em que a pesquisa transcorreu demonstra a relevância desta investigação, ao lançar luz sobre um modelo invisibilizado de gestão escolar, que traz em seu âmago a luta pelo território e pelo direito a um modo de existência singular e contra-hegemônico. A pesquisa revelou a incapacidade de as políticas públicas educacionais abraçarem a diversidade de demandas dos vários Brasis que compõem nosso país. À velha dicotomia urbano-rural, que marca nossa história moderna, acrescenta-se a dicotomia público-comunitária: a luta do MST não se resume à reinvindicação de uma escola financiada pelo Estado brasileiro (paradigma público); o movimento reclama uma escola comunitária, organizada pelos seus próprios valores, princípios e práticas.

Para concretizar essa investigação foram realizadas, em julho de 2018, entrevistas não-estruturadas com indivíduos imersos no processo já descrito. As abordagens ocorreram durante expediente normal em ambos os espaços educacionais: as escolas José Mesquita Netto e Eduardo Galeano. Em um segundo momento, também participamos de uma assembleia do setor de educação, quando foram entrevistados outros educadores. Em seguida, os áudios foram transcritos de forma literal. Na sequência, o material foi explorado por meio de uma leitura exaustiva, observando conteúdos explícitos e implícitos nas falas, transformando o corpus bruto em três percursos temáticos principais. Por fim, interpretou-se o material, selecionando trechos relevantes para o artigo, à luz do objetivo da pesquisa. Por um princípio ético, não foram revelados os nomes dos(as) entrevistados(as), mas eles(as) estão vinculados a dois grupos de atores inseridos na gestão escolar: direção e docentes.

O artigo está organizado em três seções, correspondendo aos percursos temáticos que emergiram na análise das entrevistas. A primeira trata do processo histórico que culminou com o nascimento da escola, de acordo com as demandas locais e a negociação política. A segunda seção refere-se à autonomia que a escola do campo tem em relação à escola da cidade, ainda que esteja na condição de segundo endereço, bem como a participação da comunidade escolar nas decisões da escola. A terceira seção analisa a importância do vínculo identitário para a construção de uma gestão escolar coerente com os valores e princípios do MST. E, por fim, fez-se um apanhado das conquistas e desafios da Escola Eduardo Galeano. 


\section{O processo de construção da escola}

A demanda pela criação de escolas que atendam a realidades específicas de cada comunidade é premente, caso se deseje elaborar um sistema de ensino eficiente e agregador, ao invés de enganoso e sectário. Essa afirmação é verificável quando se analisa a realidade da educação brasileira de modo geral - em que a evasão escolar é maior entre as camadas mais pobres da sociedade e que também ocupam menor espaço no ensino superior - e a realidade da educação do campo em específico, pois a herança cultural de ocupação quase integral das famílias com os afazeres do cotidiano rural precede a obrigatoriedade do estudo, garantida pela Constituição de 1988, e resulta em uma legião de trabalhadores rurais com baixa escolaridade, condição financeira limitada, morando longe das escolas e necessitando dos filhos para trabalhar em suas culturas agropecuárias.

Segundo Bourdieu (2007), para cumprir esse papel institucional excludente, basta que aqueles que administram a escola e regem as aulas ajam de forma a considerar todos iguais em direitos e deveres, sem que de fato exista igualdade fora dos muros da escola, ou, em outras palavras, "ignorem no âmbito dos conteúdos do ensino que transmitem, dos métodos e técnicas de transmissão e dos critérios de avaliação, as desigualdades culturais entre as crianças das diferentes classes sociais" (BOURDIEU, 2007: 53). Logo, a escola padroniza um modus operandi que favorece a herança cultural de uma classe burguesa letrada e acostumada à cultura erudita e à proeza verbal dos professores, enquanto as classes menos favorecidas não se identificam com o ambiente escolar e se sentem desestimuladas a dele participar.

Dessa realidade decorre a necessidade da criação de escolas do campo para moradores do campo. Desde a década de 1930, na França, já existiam as Casas Familiares Rurais (CFR), onde se desenvolveram as escolas camponesas. O termo geral para designar esses modelos de educação do campo é Centro Familiar de Formação por Alternância (CEFFA). Na atualidade, há aproximadamente 1325 CEFFA no mundo, segundo dados disponíveis no artigo A Pedagogia da Alternância praticada pelos CEFFAs (BORGES, et. al., 2012: 37). No Brasil, as Escolas de Formação do Campo (EFA) surgiram no Espírito Santo, a partir de 1969, alcançando, nas décadas seguintes, outros estados. As CFR tiveram início na década de 1980, no Sul do Brasil e, posteriormente, nas regiões Norte e Nordeste, durante a década de 1990.

Apesar das diferenças de nomenclatura entre esses grupos, para os autores do artigo citado, existe um eixo norteador comum que compreende quatro pilares divididos entre meios (associação responsável e pedagogia da alternância) e finalidades (formação integral e desenvolvimento local sustentável). A associação responsável exige a partilha do poder e a transformação do projeto político pedagógico em um espaço de debate. Junta-se a essa formação democrática a pedagogia da alternância que, para além da transição entre teoria e prática - com a divisão do tempo entre estudo e aplicação de metodologias 
que contribuam diretamente para o desenvolvimento do movimento -, também ocorre entre instituições (escola, família e comunidade), entre os diferentes saberes (populares, familiares, práticos, experienciais e teóricos) e entre os processos de formação. A finalidade é uma formação integral e emancipatória do indivíduo, aliada ao desenvolvimento local sustentável, partindo da ideia de que o desenvolvimento individual depende do desenvolvimento comunitário.

Uma professora da Escola Eduardo Galeano (docente 1) explicou que, seguindo a estrutura dos assentamentos e acampamentos do MST em todo o País, a organização em Campo do Meio também passa pela divisão em setores de acordo com a afinidade e voluntarismo das pessoas inseridas. Um dos pontos que consideramos relevante foi a participação feminina na construção do movimento, especialmente do coletivo de mulheres. Diversas mulheres, majoritariamente mães solos e advindas de um trabalho de base no estado de São Paulo, contribuem com a luta por permanência nos mais recentes acampamentos (Rosa Luxemburgo e Sidnei Dias) na área rural da cidade de Campo do Meio (MG). A educação começou a se desenvolver nesses lugares a partir da Ciranda, que era o espaço dedicado às atividades de formação para as crianças, enquanto os adultos estavam reunidos para discussões de outro nível.

A Ciranda não é só pra brincar. É pra formar também. Os pais estão reunidos hoje pra discutir qual assunto? Então vamos discutir aqui com as crianças também. Então, aí começaram a sair pessoas pra entrar no setor de educação. Então, a gente se reunia como coletivo de mulheres, mas começamos a nos direcionar pra outros setores (docente 1).

Ela enfatizou que a mobilização das mulheres no fortalecimento do setor de educação foi fundamental para conseguir ônibus em parceria com a prefeitura, possibilitando o deslocamento para as crianças estudarem na cidade. A escola itinerante ${ }^{2}$ também foi resultado dessa mobilização. Devido ao fato de as famílias estarem longe dos recursos que a cidade disponibiliza, uma das preocupações emergentes foi o fato de as crianças estarem fora da escola. Segundo a professora:

As pessoas que já eram alfabetizadas começaram a sentar com as crianças embaixo de árvores, debaixo de lona... pra educar as crianças. (...) Se o acampamento não vai mais ficar aqui por causa de um despejo, todo mundo vai junto. E a escola itinerante recebeu esse nome porque também vai junto (docente 1 ).

Segundo outra educadora, a formação do setor de educação do MST é anterior à idealização da escola e não se limitou a esse espaço. O ponto de partida foi o Programa Nacional de Educação na Reforma Agrária (Pronera), por meio da formação de alfabetizadores. Como explicou:

Algo que nos ajudou bastante foi o Pronera, que era um projeto de alfabetização. E, com esse projeto, as pessoas que tinham aptidão dentro do setor da educação iam 
fazer cursos. Eu me lembro que, em 2005, em um dos projetos, dos educadores de Minas toda, a maioria não tinha o antigo ginásio. E, com a verba que vinha, dava para formar esses educadores. Com isso, chegamos a formar algumas turmas de alfabetizados entre 2004 e 2008 e, mesmo depois que o projeto acabou, eu continuei alfabetizando as pessoas (docente 2).

A retomada formal do setor da educação se deu em 2011, com cursos de formação política nos acampamentos e com o levantamento de dados sobre os trabalhadores que desejavam terminar os estudos, inclusive daqueles com ensino médio completo que desejavam cursar o ensino superior. A docente 2 também defendeu que, durante o governo de Fernando Pimentel (PT), entre 2014 e 2018, os avanços na educação do campo foram sentidos pelo movimento:

Aí surgiu o governo Pimentel que era a nosso favor. A gente queria era uma escola nossa, mesmo. Mas não teve jeito por a gente não ter a documentação da terra. Tinha o documento que ele havia feito, mas estava em disputa na justiça. Mas, se tivesse uma escola anexa na cidade, dava (docente 2).

O apoio político que a escola recebeu do Governo de Minas Gerais, a partir de 2015, foi um ponto de convergência entre os discursos. Esse governo sofreu diversas críticas, quando, diante da obrigatoriedade de ajuste à lei de responsabilidade fiscal, decidiu privilegiar alguns setores e pagar com atrasos e parcelamentos os salários dos servidores da educação. Por outro lado, foi durante esse governo que a luta do MST pela conquista do território teve maiores avanços. Na área em disputa funcionava a Usina Ariadnópolis Açúcar e Alcool S/A. A escritura do terreno estava em nome da Companhia Agropecuária Irmãos Azevedo (Capia), que faliu em 2002. Desde 1997, quando as atividades da usina já estavam suspensas, o MST começou a organizar uma ocupação no local. Atualmente, a estimativa é de que 600 famílias morem nessas terras. O diretor da escola explicou que a terra ainda é do Instituto Nacional de Colonização e Reforma Agrária (Incra), mas existem latifundiários interessados em se apossar da região. Segundo ele, o Governo de Minas apoiava (gestão 2014-2018), mas não houve condições jurídicas de assumir a propriedade. A disputa pela área de 3,6 mil hectares dura 16 anos. Ao longo da entrevista, o diretor enfatizou sua cobrança durante a visita da secretária de educação do Governo Pimentel, Macaé Evaristo:

A Sra. secretária de educação em exercício no ano passado, a Macaé, ela esteve lá. Eu conversei com ela e falei assim: Sra. secretária, o que nós vamos fazer para ajudar em todos os sentidos a educação do campo? Porque, desde setembro de 2016, a Secretaria, infelizmente, não disponibilizou recursos para a educação no campo (direção).

A docente 1 contou que, com o apoio governamental, foi feita uma catalogação das famílias por meio de uma ficha e foi perguntado se os membros de cada família tinham interesse em voltar a estudar. 
Em parceria com o governo, a gente começou a fazer ficha e procurar demanda. Então, a gente tem todo um arquivo de cadastro das pessoas, né? Nome do pai, nome da mãe. Quem tá aqui nesse lote acampado. Você é adulto, mas qual é a sua formação? Você tem interesse de voltar a estudar? (docente 1).

Ciente de que havia demanda para abrir a escola, o passo seguinte foi lidar com o problema do endereço, uma vez que o local onde se pretendia colocá-la em funcionamento não pertence ao MST (está em disputa judicial). Segundo a docente 1, houve um minucioso processo de avaliação das condições estruturais do local. Em um primeiro momento, tentaram abrir a escola aproveitando as edificações da usina, localizada no território ocupado, mas, após negociações e ameaças de despejo, a escola migrou para uma construção próxima. Por meio de mutirões e do envolvimento da comunidade, o movimento conseguiu criar condições para que o local escolhido pudesse receber uma escola. Além disso, foi necessário associá-la a uma escola estadual urbana, para solucionar o problema da ilegalidade do endereço:

Foram várias reuniões entre nós e conseguimos a demanda. Nós temos crianças, jovens e adultos para construir a escola do campo. Só que aí a gente precisava de um espaço. Nós temos a filosofia que embaixo de uma árvore pode, mas para o Estado não. Então vieram aqui engenheiros, arquitetos, mas aí parava na hora do endereço. Na verdade, nós ainda não temos um endereço porque a terra tá em negociação. Mas aí veio gente aqui e disse que não podia porque "tava" sujo, porque não tinha fio. Aí nós conseguimos parceiros: universidades, professores, parceiros nossos que vêm fazer trabalhos aqui. E aí fizemos vários mutirões, porque aqui era coberto de esterco. Pro Estado chegar aqui e dizer que realmente vai ter condição para fazer. (...) Só que pra ter a nossa secretaria aqui com diretor e vice-diretor precisa ter um número ' $x$ ' de alunos. Aí, então, a gente pode ser um anexo de uma escola do Estado. Então, na cidade, o diretor topou, e foi um outro trabalho feito com ele (docente 1).

A partir daí, as primeiras turmas abertas foram de educação para jovens e adultos (EJA) e, em 2018, também foi implementado o $6^{0}$ ano regular do ensino fundamental. A luta pela conquista das terras continua e, frequentemente, os membros do MST em Campo do Meio organizam caravanas e acampam na Assembleia Legislativa de Minas Gerais com a intenção de cobrar que o governo legalize a permanência do movimento nas áreas da Usina de Ariadnópolis.

\section{Autonomia e participação da comunidade escolar}

A criação da escola, ainda que contasse com o apoio da direção, não garantia a aplicação do modelo pedagógico e de gestão do movimento, uma vez que a ligação direta com a SEE colocava a escola em uma posição de conflito, caso as ordens da Secretaria não fossem condizentes com as ideias do movimento. Por outro lado, o Artigo 14 da Lei 
de Diretrizes e Bases da Educação defende que "os sistemas de ensino definirão as normas da gestão democrática do ensino público na educação básica, de acordo com as suas peculiaridades" (BRASIL, 1996), considerando a participação dos profissionais da educação na elaboração do projeto político pedagógico e a participação das comunidades escolar e local em conselhos escolares. O Artigo 15 da mesma legislação complementa, afirmando que "os sistemas de ensino assegurarão às unidades escolares públicas de educação básica que os integram progressivos graus de autonomia pedagógica e administrativa e de gestão financeira" (BRASIL, 1996).

O Plano Nacional de Educação (PNE), edição 2014-2024, responsável por planejar a dinâmica do sistema educacional brasileiro na década em foco, estipulou, em sua meta 19, um prazo de apenas dois anos para que se assegurassem condições "para a efetivação da gestão democrática da educação, associada a critérios técnicos de mérito e desempenho e à consulta pública à comunidade escolar, no âmbito das escolas públicas, prevendo recursos e apoio técnico da União para tanto" (BRASIL, 2014). Entretanto, a aplicação de um conceito de gestão democrática que consideramos realmente eficaz passa por uma participação efetiva da comunidade escolar na construção do projeto político pedagógico, a fim de considerar demandas específicas da realidade em que está inserida. Essa visão alinha-se ao pensamento de Marques (2014: 464):

Desta perspectiva, a defesa da democratização da gestão não se dá por ela própria ou como um fim em si mesmo. Ela constitui uma das estratégias que tem por finalidade a busca da melhoria da qualidade da educação, dentre outras maneiras, por meio da elaboração de um currículo que tome por base a realidade local, da construção de práticas cotidianas que possam integrar os sujeitos que fazem o dia a dia da escola: diretor, professores, estudantes, coordenadores, técnico-administrativos, vigias, auxiliares de serviços, em estreita articulação com a comunidade na qual ela se encontra inserida.

Na obra A educação na cidade, Paulo Freire, na época secretário de educação municipal de São Paulo, discorreu sobre a necessidade de criação de assembleias populares que serviriam para integrar alunos e pais na elaboração de projetos educacionais. Freire defendeu que "através delas é possível que se dê em nível profundo uma real participação da comunidade de pais e representantes de movimentos populares na vida inteira das escolas" (FREIRE, 1991: 48). Isso porque "a democratização da escola não pode ser feita como resultado de um ato voluntarista do secretário, decretado em seu gabinete" (FREIRE, 1991: 48).

Na prática, algumas escolas públicas estaduais na Região Sul de Minas Gerais, observadas durante o exercício da docência de um dos pesquisadores-autores deste artigo, possuem uma estrutura relativamente democrática. Os diretores e vice-diretores são eleitos para mandatos de três anos. Os especialistas, professores, auxiliares técnicos e auxiliares de serviços gerais ingressam na escola por concursos de ampla divulgação ou por meio de contratos temporários firmados por editais de seleção - que levam em conta o tempo de contribuição 
para a educação estadual, a formação e a idade dos candidatos. Nas escolas, o órgão deliberativo mais importante é o colegiado, que conta com profissionais das áreas financeira e administrativa, além de outros funcionários eleitos entre os seus pares. As questões que extrapolam os limites da escola são solucionadas pela Superintendência Regional de Ensino (SRE) e, se necessário, pela Secretaria do Estado de Educação (SEE).

Por outro lado, essa estrutura democrática representativa é enfraquecida pela verticalidade na tomada de decisões, que fluem dos órgãos superiores para os inferiores de forma autoritária. O que ocorre, frequentemente, é que os anseios, preocupações e opiniões dos membros com menor poder de decisão não são discutidos coletivamente e, após a eleição, a gestão democrática nas escolas é enfraquecida significativamente. O capítulo A teoria da ação dialógica e suas características, que encerra a obra Pedagogia do Oprimido (FREIRE, 2016), demonstra o repúdio do autor às relações verticais e autoritárias dentro do ambiente escolar, nas quais aqueles com menor poder de decisão são coisificados para atender e seguir as proposições daqueles que detêm cargos de maior poder de decisão. De acordo com Freire (2016), a adesão a um projeto passa pelo reconhecimento da realidade-problema à qual os sujeitos estão expostos e pelas respostas que darão para solucionar as demandas.

As escolas do MST inseridas no contexto dos modelos públicos estaduais e municipais interpretam e aplicam os artigos 14 e 15 da LDB de uma outra forma, alinhando-se à "[...] ideia de controle da escola pelas forças populares, ou seja, por professores, funcionários, alunos, pais e comunidade local" (DAL RI, VIEITEZ, 2010: 56). A gestão coletiva, nesse caso, implica a divisão de tarefas, conforme as qualidades e aptidões de cada membro dessa comunidade escolar, seja na manutenção e conservação da escola, nas unidades de produção ou na administração. Na Escola Eduardo Galeano, as decisões eram tomadas, principalmente, pelo setor de educação, formado por membros voluntários e convidados, compondo um grupo com cerca de 12 pessoas, e outras ações específicas eram decididas em assembleias gerais convocadas esporadicamente e incluíam todos os setores do MST.

O que se observou, na análise das entrevistas, foi que a identificação dos membros da comunidade escolar era maior do que a experimentada em outras escolas estaduais, pois o aluno e sua família estavam inseridos efetivamente na estrutura organizacional, que era o acampamento ou o assentamento. Entretanto, esse modelo de gestão escolar encontrava obstáculos quando conectado ao aparelho burocrático do Estado, que ia desde a alocação de professores, auxiliares de serviços gerais e técnicos, feita pelas SRE, o que, por vezes, implicava a inserção de indivíduos sem identificação com o movimento, até a administração financeira e a tomada de decisões. Notamos que os recursos necessários para a manutenção e funcionamento da escola - como alimentos, produtos de limpeza e material didático - estavam sujeitos à racionalização orçamentária feita pelo próprio diretor em função do número de alunos em cada unidade. A direção procurou justificar como planejava a divisão de recursos entre as escolas: 
Como a escola lá não está totalmente legalizada, existem situações que dificultam chegar recursos pra essa escola do campo. Lá hoje nós temos em torno de 40 alunos e não vem recurso pra eles. Então o que eu faço? Onde eu comprava dois quilos de carne, eu compro três. Onde eu comprava uma caixa de óleo, eu compro uma caixa e meia pra poder atender a educação do campo. E, mesmo assim, ainda fica a desejar. Mas com planejamento a gente sempre consegue mandar recursos: alimento, produto de limpeza... (direção).

O próprio cardápio era determinado pela SEE, entretanto, devido à especificidade da Escola Eduardo Galeano, era comum que os alunos doassem alimentos, uma vez que eram produtores rurais. Mas essa especificidade não era considerada pelo planejamento burocrático, que opera por meio de uma regra padrão.

As reuniões pedagógicas talvez representem um dos pontos em que a divergência de demandas e realidades entre a escola do campo e a escola urbana fossem maiores. De acordo com a legislação atual em Minas Gerais, o professor que tem um cargo completo deve lecionar 16 aulas semanais e cumprir quatro horas extraclasse divididas entre duas horas de atividades na escola e duas horas de reunião pedagógica. Portanto, as escolas são obrigadas a realizar semanalmente as reuniões. Nesse espaço são discutidos problemas gerais e específicos que envolvem a comunidade escolar. São estabelecidos debates e propostas soluções com maior ou menor grau de participação efetiva dos envolvidos de acordo com o perfil dos gestores. Observamos várias tensões entre ambas as escolas, a começar pela dificuldade em marcar reuniões conjuntas entre os professores da cidade e do campo:

Eu tento envolver ao máximo os professores. O que acontece com o corpo docente? A maioria trabalha em duas escolas. Então nós temos que marcar uma reunião pedagógica pra discutir o projeto político pedagógico. Na segunda não tem como, na terça não tem, na quarta, quinta, na sexta. No sábado tem como? Tem. Então vamos marcar que horas? Infelizmente nós não conseguimos ainda firmar essa reunião no sábado. O que eu faço? Procuro convidar os professores da educação do campo a participar junto com os professores da cidade. Os problemas vão ser um pouco diferentes, mas eu tento fazer esse envolvimento. Eu tento fazer com que eles opinem baseado na realidade da escola de lá, porque são diferentes. A gente tenta fazer com que todos participem, mas ainda existem questões lá na escola que estão como âncora pra que a escola não vá (direção).

Por outro lado, a docente 1 justificou que os professores engajados que davam aula no campo se reuniam dentro do movimento, em especial com o setor de educação, e dedicavam mais tempo do que o necessário em atividades voltadas à escola, uma vez que se envolviam em múltiplas demandas do cotidiano escolar. Sobre as reuniões pedagógicas, ela argumentou:

Nós temos um grande problema com esse negócio de reunião pedagógica. A gente tem a supervisora designada que é da cidade. Então ela veio, mas a gente fazia as reuniões pedagógicas entre nós. Só eu e o fulano [substituímos o nome original] somos professores do movimento. Todos os outros professores e, inclusive a 
supervisora, são da cidade. Nós conseguimos as meninas da cozinha. A Penha é uma e a Sonia é do período da tarde. E é gente nossa. Mas esse ano a gente ainda não conseguiu fazer uma reunião pedagógica decente. As primeiras a gente fazia junto com o setor de educação. Nós não somos cobrados pra ir nas reuniões pedagógicas da cidade, mas o movimento vive em reunião. Porque a gente tem muita coisa pra discutir. A outra supervisora já vinha aprendendo. Mas nós estamos com a supervisora [especialista] nova e estamos tentando mostrar o que acontece. Eu chego duas horas da tarde e vou embora dez horas da noite (docente 1).

Observações sobre a atuação da especialista também apareceram na fala da docente 2. Nas escolas, os(as) especialistas têm como função supervisionar o trabalho dos professores, analisar seus planos de aula e avaliar seu desempenho. Entretanto, pareceu-nos problemático que um indivíduo, sem prévio conhecimento do universo político e social do MST, recebesse a incumbência de avaliar os méritos dos profissionais envolvidos, mesmo considerando que a escola do campo é que foi anexada à escola da cidade. Ainda assim, seria desejável que o(a) especialista participasse das diferentes realidades e compreendesse as demandas apresentadas pelas partes. $\mathrm{O}$ mesmo se aplica aos professores. Um educador que não se interessa pela realidade do aluno estará destinado ao insucesso. Soma-se ao problema da identidade periférica associada ao $\mathrm{MST}^{3}$ um outro desafio de natureza burocrática, uma vez que, na escola do campo, havia a participação de educadores que não tinham licenciatura plena. Na avaliação da docente 2:

A gente sabia que, além de estar supervisionando o trabalho, ela também estava vigiando. E eu mesmo fui uma que bati de frente muitas vezes com ela. É uma pessoa muito bacana, mas a gente sabia que estava ali pra vigiar, no leva e traz. E a gente via que tinha professor que estava querendo tirar proveito do que nós somos. Elá é totalmente diferente do que é a nossa pedagogia. Eu cheguei muitas vezes em que a gente tinha reunião pedagógica, no começo, a ir com outra pessoa do setor da educação e ouvir que a gente era inconveniente porque nós não temos pedagogia no nível de faculdade. Eu falei que realmente eu não tenho, mas a pedagogia do ensino tá aqui, olha! Eu falei pra eles, mas paramos de ir (nas reuniões). Então nunca funcionou do jeito que a gente queria, mas nós fazíamos funcionar aqui dentro da escola. Eu mesmo ia muito na escola e me propus, quando encontrava aquele problema do adulto que tinha feito a terceira ou quarta série primária, mas ele não estava alfabetizado. Aí sabe o que a supervisora disse? Que se chegar alguém do Estado vai encontrar uma estranha dentro da escola. Todos os que estavam ali nunca tinham alfabetizado adulto. Claro que eles poderiam conseguir alfabetizar, como conseguiram. Mas com o método que eu tenho e os cursos que eu fiz nessa época do Pronera em uma universidade lá em Belo Horizonte eu tenho base para educar adultos (docente 2).

É oportuno incluir nessa análise a dimensão identitária (que será melhor explorada no próximo tópico), ou seja, a percepção dos membros do MST, de outros setores da esquerda política de que existe uma campanha nacional, que não começou recentemente, com a intenção de criminalizar movimentos sociais e sindicatos. Com forte apelo midiático, essa campanha teve o resultado esperado de estimular uma grande parcela 
da população a manifestar aversão a esses movimentos e ao modo como atuam, mesmo que seja presumível que o conhecimento de boa parte dessas pessoas sobre os valores norteadores e o plano de lutas dos movimentos seja apenas superficial. Há também o fato de que a defesa do MST por uma reforma agrária que sobreponha a agricultura familiar sobre a política latifundiária do agronegócio gera um descontentamento dos grandes proprietários do campo. A construção de um imaginário social negativo sobre o MST - associado, muitas vezes, a conflitos ilegítimos com os grandes latifundiários - opera justificando os problemas de origem externa que afetavam a escola. Sobre esse aspecto, a direção comentou:

Nós temos professores que abraçaram a causa e acompanham a realidade e veem a necessidade daquele povo. Mas, infelizmente, eu sinto que existem fatores não educacionais que interferem para a progressão da escola. Eu estou falando da politicagem. Nós temos alunos que dependem do transporte municipal. Mas a prefeitura alega que não possui uma logística pra ficar levando os alunos praquela escola. Interfere. Porque não vai ter uma sequência pedagógica. E o corpo discente da noite são pessoas mais idosas (direção).

A docente 1 também falou sobre a falta de apoio da prefeitura, alegando que a educação infantil e fundamental 1 - até o 5ํo ano - geralmente está a cargo das secretarias municipais de educação, enquanto o ensino fundamental 2 e o ensino médio são de responsabilidade do estado. A preferência daqueles que participaram da fundação da escola era por começar com os anos iniciais, mas, devido ao desinteresse da secretaria municipal, tiveram que recorrer ao estado e começar pelo $6^{\circ}$ ano do ensino fundamental, precisamente com o EJA, porque, como revelado anteriormente, as condições estruturais nos primeiros meses de funcionamento da escola ainda não eram ideais.

Outro empecilho político mencionado por essa professora foi referente aos assédios e ameaças direcionados aos funcionários da escola. O episódio remete ao momento em que o secretário da escola urbana esteve no acampamento para realizar as matrículas dos alunos dentro da usina. Devido às ligações e ameaças feitas pelos grupos latifundiários contrários à ocupação do MST, as matrículas tiveram que ser feitas na cidade, gerando um problema maior de locomoção para as pessoas que desejavam voltar a estudar.

\footnotetext{
A gente começou a fazer a matrícula. A direção disponibilizou o secretário dele pra vir aqui fazer as matrículas. Só que aí a gente tinha ligação das pessoas da usina dizendo que a gente "tava" contra a lei e intimidando a direção. Então a direção passou por uns apuros também. Imagina? Tá lá dentro o secretário dele de repente baixa a polícia porque estamos fazendo coisa irregular. Mas não era. Tivemos que convencer a direção que nós estamos legalmente apoiados. Mas não teve jeito. Nossos alunos tiveram que ir pra cidade fazer matrícula. E aí nós, militantes, tivemos que fazer plantão pra que os alunos fizessem a prova de reclassificação e viessem pra gente. Tem muita gente que não é do nosso lado e trabalha na secretaria da escola, a gente sabe disso. Então falavam (para o aluno): "não... tá faltando documento". Mas não "tava" faltando (docente 1).
} 
As divergências políticas e as informações superficiais sobre o movimento pareceram ser os maiores obstáculos para o desenvolvimento da escola. Ficou visível, durante as entrevistas, que existia desinteresse de muitos funcionários em contribuir para o projeto educacional do MST. Essa apatia devia-se a diversos fatores, já que qualquer professor que trabalha na rede estadual de Minas Gerais está exposto a muitos obstáculos que tornam o seu labor exaustivo e desmotivador. Por outro lado, os objetivos do setor de educação do MST pareciam mais próximos de serem alcançados quanto mais os diferentes atores que compunham esse cenário sentiam-se identificados e envolvidos com o movimento. Nessa perspectiva, a próxima seção foca em como a luta por reconhecimento travada pelo MST na sociedade brasileira reverbera no caso em estudo. No centro do conflito estavam duas reivindicações relevantes, uma mais imediata: a criação de matriz curricular própria, que representasse o movimento; e outra de natureza mais ampla - o direito do MST de estabelecer um modo de existência singular, alinhado à visão de mundo e às práticas defendidas pelo movimento. $\mathrm{O}$ aspecto subjacente em ambas as reinvindicações estava na tentativa de cooptação, pelo público-governamental, da potência da diversidade comunitária.

\section{Identidade e formação para o campo}

As escolas públicas brasileiras, via de regra, são um ambiente de descontentamento para os atores que participam de seu cotidiano. Os professores lidam diariamente com os aborrecimentos da vida profissional burocrática e exaustiva, além de terem que enfrentar as pressões do trabalho que, com frequência, partem de gestores autoritários que mantêm uma relação verticalizada. Os alunos não reconhecem, dentro da escola, nada que se pareça com a sua vida fora dela e, assim, não criam identificação com as atividades realizadas nesse espaço. Os próprios gestores têm que administrar diversos conflitos familiares ou trabalhistas, bem como as pressões igualmente verticalizadas que exigem uma gestão que dê conta de todos os prazos.

Uma das possibilidades para minimizar a tensão dessas relações escolares é começar a pensar cada escola como sendo única, com um público de alunos e demandas específicas. A estratégia adotada historicamente no Brasil tem sido exatamente o contrário. No estado de Minas Gerais, por exemplo, documentos como o Currículo Básico Comum (CBC) e o Currículo Referência determinam qual conteúdo deve ser ensinado em cada disciplina de acordo com o nível escolar, desconsiderando a realidade singular das escolas. Avaliações externas, como a Prova Brasil e a Olímpiada Brasileira de Matemática, tendem a medir os alunos do País inteiro com a mesma 'régua' e categorizar as melhores e piores escolas de acordo com o rendimento de seus alunos, mais uma vez desprezando 
que os estudantes de uma determinada escola possam ter mais obstáculos ao aprendizado que os de outra.

A alocação de professores para as escolas é feita pela SEE. Em parte, essa formalidade é necessária para evitar o clientelismo no processo seletivo. Porém, no caso do MST, isso se constituía em um problema, uma vez que alguns professores empregados na escola não se identificavam com os valores e a pedagogia do movimento. Esse problema foi destacado pela direção:

Quando vieram pra implantar essa escola, eu falei: eu preciso aprender educação do campo. Mas não adianta o fulano [substituímos o nome] estudar, não adianta o professor a ou b estudar. Todos têm que estudar. Todos têm que se envolver. Então ainda pecamos na união. Em sentar e pensar na escola do campo, que é um desafio para todos nós, né? (direção).

A Escola Eduardo Galeano foi compreendida nesta pesquisa como um instrumento de preservação cultural e política do movimento, uma vez que tinha como intenção manter o indivíduo ligado à terra e identificado com o espaço ao qual pertence - esse olhar pode ser estendido às escolas do MST em geral. Por outro lado, a busca por um reconhecimento oficial fazia com que essa identificação fosse enfraquecida pela estrutura educacional padronizadora do estado. Para Nora Gluz (2013), o conceito de educação pública associou-se à ideia de educação estatal como uma forma de garantir a integração social por meio do acesso à escola. Por conseguinte, a autonomia de projetos de educação oriundos dos movimentos sociais foi minada, uma vez que se tornaram reféns do reconhecimento oficial.

Uma das questões identitárias que emergiram como fundamentais, durante a pesquisa, diz respeito à matriz curricular específica para as escolas do campo. A direção da escola esclareceu que procurou, junto à SRE, encontrar uma matriz curricular estadual que estivesse direcionada às demandas e realidades específicas das escolas rurais. Entretanto, só existe essa regulamentação para o EJA. Sendo assim, os alunos da Escola Eduardo Galeano que cursavam o $6^{0}$ ano regular do ensino fundamental tiveram que se inserir em um modelo curricular bastante generalizado, o que pareceu ser um problema também para os professores, conforme depoimentos dos docentes e da direção:

A gente tinha o EJA e conseguiu que a grade (matriz curricular) fosse voltada para a educação do campo. A gente fazia as reuniões pedagógicas entre nós, para montar planejamento e tudo. Aí agora mudou o ano e mudou também a supervisora. E nós começamos o ano com uma classe regular de $6^{0}$ ano, que nós não conseguimos mudar a matriz curricular, que é a mesma da cidade (docente 1).

A educação do campo é uma coisa nova pra nós e para a superintendência. A gente esbarra em coisas que nós ainda não conhecemos. Na educação do campo, pelo que nós buscamos junto a Secretaria Estadual de Educação, existe uma matriz curricular somente para o EJA. (...) Já para o sexto ano regular não tem uma matriz curricular voltada para a educação do campo. O que os professores que trabalham ali tentam 
fazer? Eles trabalham o conteúdo e, dentro daqueles conteúdos, eles tentam fazer temas transversais voltados para o campo. Uma horta, água, parte de terra. Eles tentam trabalhar, mas fica difícil fugir muito da matriz (direção).

Dentro do contexto escolar em que estão inseridos alunos, professores e gestores, o conceito de identidade tem papel fundamental no sucesso da relação ensino-aprendizagem e na satisfação daqueles que participam desse ambiente. Assim como modelos padronizados de avaliações externas não dão conta de contemplar as diferentes realidades que se pode encontrar em cada escola, também os professores e gestores têm melhores resultados quando estão cientes do público com o qual estão lidando. Uma professora explicou que o MST oferece cursos de formação por região, estado, macrorregião e também nacionais. Nesses cursos, os participantes escolhidos em suas bases têm a oportunidade de discutir questões específicas da educação no MST, suas demandas e estratégias bem-sucedidas. Sobre a sua própria experiência, ela contou:

Então, as pessoas que participam do setor de educação têm também essas atividades fora. E assim vai formando militantes. Eu participei de um que aconteceu no Mato Grosso, já deve fazer uns dois anos. E aí vem gente de todo lado. É muito rico. Você fica vinte dias, geralmente em janeiro, e aprende muito sobre a pedagogia do movimento (docente 1).

A professora também relatou que existe uma iniciativa recente de formação voltada ao público infantil do MST. O projeto tem o nome de Encontro Nacional dos Sem-Terrinha. Além disso, destacou que é importante a formação das crianças dentro do MST para que desejem permanecer na terra e dar continuidade ao movimento. Comentou, ainda, que muitas dessas crianças não se adaptam às escolas da cidade e sofrem assédio moral dos professores e alunos. Esse assédio pode acabar estimulando-as a ter vergonha de sua origem e da ocupação dos pais, incentivando-as a migrar para o espaço urbano:

Vão participar crianças de 8 a 11 anos. Eles vão ter espaço de leitura, mesa de debate. Ejá teve crianças nossas que foram pra Brasília, e eles vão ser os coordenadores. (...) A gente quer formar gente nossa e crianças que vão gostar de morar no campo. Porque depois quem vai dar continuidade para o lote do pai que tá recebendo as terras agora, né? Então a criança vai pra escola com o pé sujinho de terra e tem professora que fala assim: "olha a sujeira que você tá fazendo aí. Vai lá buscar uma vassoura". A criança vai ela mesmo criando um preconceito com a terra, e a gente aprende o contrário, que terra é vida. Da terra a gente tira o alimento. A gente quer a nossa escola pra criança ter admiração pelo o que o pai faz. E pras crianças levarem o que elas aprendem para o pai (docente 1).

O envolvimento dos mais novos com o movimento parece ser fundamental para semear nesses indivíduos a vontade de permanecer no campo e valorizar o estilo de vida e trabalho contido nesse espaço. Durante a entrevista da docente 2, ela explicou que: 
Eu não perdi o vínculo com a roça porque fui alfabetizada na roça. Mesmo eu tendo saído com treze anos da roça, eu trouxe os valores, trouxe a raiz dentro de mim. Então a gente não concorda em tirar o menino daqui pra estudar lá (docente 2).

Nesse sentido, o aluno que frequenta a escola do campo - e, especialmente, a escola do MST - está incluso em um ambiente de formação escolar e política no qual é possível reconhecer não apenas os conteúdos ligados à sua prática cotidiana do trabalho rural, como também os valores políticos e culturais que norteiam o movimento ao qual pertence. Não se trata, pois, de fechar as portas de acesso à interação com o espaço urbano, para a criança ou adolescente da zona rural. A formação do morador do campo em uma escola do campo, longe de ser um processo excludente, cria uma identificação com o espaço de aprendizagem e contribui para que esse indivíduo alimente a vontade de permanecer no campo, o que é desejável para o movimento.

\section{Considerações finais}

A Escola Eduardo Galeano enfrentou muitos desafios para sua manutenção. Em um cenário de diminuição da população infanto-juvenil do Brasil, a opção adotada por muitos governos estaduais e prefeituras é pelo fechamento de escolas rurais. Na contramão desse processo, o MST em Campo do Meio se esforçou para fortalecer a educação no campo e para o campo. Sendo assim, teve como objetivo claro formar indivíduos conscientes do seu papel político e militante ao promover a permanência no campo. O apoio da direção à construção e fortalecimento da escola foi um ponto que contribuiu para o sucesso temporário da empreitada. Ainda assim, a alocação de servidores por meio de editais constituiu-se em empecilho para a consolidação de um quadro de funcionários engajados com o movimento, que pudessem receber a formação necessária para lidar com as demandas específicas da educação do campo. Essa vontade de compreender, decidire agir materializa-se no pensamento de Paulo Freire, na importância do diálogo autêntico que se dá quando os envolvidos no processo comunicativo compartilham um propósito mais amplo, percebido como algo pelo qual vale a pena lutar.

\footnotetext{
Educador e educandos, cointencionados à realidade, se encontram numa tarefa em que ambos são sujeitos no ato, não só de desvelá-la e, assim, criticamente conhecê-la, mas também de recriar este conhecimento. Ao alcançarem, na reflexão e na ação em comum, este saber da realidade, se descobrem como seus refazedores permanentes. Deste modo, a presença dos oprimidos na busca de sua libertação, mais que pseudoparticipação, é o que deve ser: engajamento (FREIRE, 2016: 101).
}

O trecho acima faz parte do capítulo Ninguém liberta ninguém, ninguém se liberta sozinho: os homens se libertam em comunhão. $\mathrm{O}$ título do capítulo é também uma reflexão para seus 
leitores e perfeitamente transferível para o contexto analisado neste artigo. Os membros do MST, enquanto oprimidos pelo contexto agrário em que estão inclusos, procuraram meios de formar e mobilizar aqueles que viessem a fazer parte da construção do projeto da escola, pois viviam em uma relação de interdependência. Somente através do engajamento é que pessoas que não vivem o cotidiano do movimento poderão compreendê-lo e por ele lutarem.

Nesse sentido, a experiência em Campo do Meio mostrou-se demasiadamente didática, na medida em que revelou a capacidade transformadora de um grupo de indivíduos organizados coletivamente no intuito de promover uma gestão engajada e obstinada em conquistar os objetivos traçados pelo MST. Em que pese possíveis discordâncias da população em geral sobre o MST - em relação às demandas ou ao modo como atuam na luta pela reforma agrária -, é inegável que o movimento conseguiu, por meio da experiência na Escola do Campo Eduardo Galeano, algo que outras escolas estaduais urbanas têm enorme dificuldade em alcançar, que é a participação efetiva da comunidade escolar. Esse engajamento foi fundamental para que a gestão escolar praticada pelo MST pudesse ser considerada, de fato, democrática e participativa.

Recebido em 05/05/2020. Aprovado em 25/06/2020.

\section{Notas}

1 Na linguagem do MST, acampamento refere-se aos territórios ocupados pelo movimento, mas os membros não detêm a posse legal.

2 Nome dado pelos membros do MST, como consta na citação na sequência.

3 Identidade diz respeito a processos históricos de significação construídos culturalmente por meio de interações assimétricas. Em nossa visão, a disputa por uma hegemonia identitária é um dos importantes aspectos que está em questão nas lutas sociais, pois o poder de definir o significado das coisas, pessoas, iniciativas e movimentos depende do lugar que se ocupa no sistema de relações sociais, ou seja, depende das relações de poder.

\section{Referências}

BOURDIEU, Pierre. Escritos de Educação. 9. ed. Petrópolis: Vozes, 2007.

BORGES, Idelzuith Sousa. et. al. A Pedagogia da Alternância praticada pelos CEFFAs. In: Territórios Educativos na Educação e no Campo: escola, comunidade e movimentos sociais. $2^{2}$ edição, Belo Horizonte, Editora Gutemberg, 2012.

BRASIL. Lei no 9.394, de 20 de dezembro de 1996. Estabelece as diretrizes e bases da educação nacional. Disponível em: http://www.planalto.gov.br/ccivil_03/Leis/L9394.htm. Acesso em: 02 jun. 2020. 
BRASIL. Lei no13.005, de 25 de junho de 2014. Plano Nacional de Educação - PNE. Disponível em: http:// portal.mec.gov.br/arquivos/pdf/pne.pdf. Acesso em: 02 jun. 2020.

BRUNO, Lúcia. Poder e administração no capitalismo contemporâneo. 11ª edição, Petrópolis, Editora Vozes, 2016.

DAL RI, Neusa Maria. VIEITEZ, Candido Giraldez. A educação do movimento dos sem terra: Instituto de Educação Josué de Castro. Educ. Soc., Campinas, v. 25, n. 89, p. 1379-1402, set./dez. 2004.

DAL RI, Neusa Maria; VIEITEZ, Candido Giraldez. Gestão democrática na escola pública: uma experiência educacional do MST. Revista portuguesa de educação, Minho, v. 23, n. 1, p. 55-80, jun./nov. 2010.

FREIRE, Paulo. A educação na cidade. São Paulo: Cortez, 1991.

FREIRE, Paulo. Pedagogia do oprimido. 60. ed. Rio de Janeiro: Paz \& Terra, 2016.

GLUZ, Nora. Las luchas populares por el direcho a la educación: experiencias educativas de movimentos sociales. 1. ed. Buenos Aires: Clacso, 2013.

MARQUES, Luciana Rosa. Gestão democrática da educação: os projetos em disputa. Revista Retratos da Escola, Brasília, v. 8, n. 15, p. 463-471, jul./dez. 2014.

OLIVEIRA, Dalila Andrade. Gestão democrática da educação. 11. ed. Petrópolis: Vozes, 2016. 